\title{
Dietary flavanols exert different effects on antioxidant defenses and apoptosis/proliferation in Caco-2 and SW480 colon cancer cells
}

Sonia Ramos*, Ildefonso Rodríguez-Ramiro, María Angeles Martín, Luis Goya and Laura Bravo

Department of Metabolism and Nutrition

Instituto de Ciencia y Tecnología de Alimentos y Nutrición (ICTAN, former Instituto del Frío)

Consejo Superior de Investigaciones Científicas (CSIC)

José Antonio Novais 10

Ciudad Universitaria, 28040, Madrid

Spain

Phone: +34.91 .544 .56 .07$

Fax: +34.91.549.36.27

* Corresponding author: e-mail: s.ramos@ictan.csic.es. 


\begin{abstract}
$^{1}$
Flavanols intake has been associated with reduced risk of cancer. In this study, the anticarcinogenic effects of the flavanols epicatechin (EC), epicatechin-gallate (ECG) and procyanidin B2 (PB2) on Caco-2 and SW480 colon cancer cells were investigated. Catechins showed different cytotoxicity depending on the cell line. ECG displayed strong growth inhibitory effects against SW480 cells, but was ineffective on Caco-2 cells. In contrast, PB2 did not affect Caco-2 cells, whereas promoted cell growth in SW480 cells and EC had no obvious effects on any cell line. Exposure of SW480 cells to ECG led to apoptosis as determined by caspase-3 activity, imbalance among Bcl-2 anti- and pro-apoptotic protein levels, ERK activation and AKT inhibition, whereas PB2 treatment enhanced phospho-AKT and phospho-ERK levels. Incubation of Caco-2 cells with ECG increased glutathione levels without affecting the expression of pro- and anti-apoptotic Bcl-2 proteins, AKT or ERK. The results suggest that the different cytotoxicity of flavanols is caused by their different activity and the degree of differentiation of the colon cancer cell line. Thus, ECG induced apoptosis in SW480 cells and contributed to the cytotoxic effect, whereas ECG enhanced the antioxidant potential in Caco-2 cells. PB2 activated cell proliferation and survival/proliferation pathways in SW480 cells.
\end{abstract}

Keywords: Epicatechin, epicatechin gallate, procyanidin B2, colon cancer, apoptosis, survival/proliferation.

\footnotetext{
${ }^{1}$ Abbreviations: AKT/PKB, protein kinase B; BrDU, 5-bromo-2'-deoxyuridine; CRC, colorectal cancer; DCFH, 2',7'-dichlorofluorescin diacetate; DTT, dithiothreitol; EC, epicatechin; ECG, epicatechin gallate; EGCG, epiagallocatechin-3-gallate; ERK, extracellular regulated kinase; FBS, fetal bovine serum; GSH, glutathione; GPx, glutathione peroxidase; GR, glutathione reductase; GST, glutathione-S-transferase; LDH, lactate dehydrogenase; LY294002, 2-(4-morpholinyl)-8-phenyl-1(4H)-benzopyran-4-one hydrochloride; PB2, procyanidin B2; PD98059, 2-(2-amino-3-methoxyphenyl)-4H-1-benzopyran-4-one; OPT, $o$-phthaldehyde; ROS, reactive oxygen species; $t$-BOOH, tert-butylhydroperoxide.
} 


\section{Introduction}

There is growing interest in the use of natural products to aid in the maintenance of human health. In particular, catechins have been receiving increasing attention. (-)-Epicatechin gallate (ECG), ()-epicatechin (EC) and procyanindin B2 (PB2) are catechins abundant in tea and/or cocoa (Babich et al., 2005; Lamuela-Raventós et al., 2005). These foodstuffs are widely consumed and have increasingly attracted researchers, food manufacturers, as well as consumers due to their health benefits, including the prevention of cancer (Ramos, 2007; Vinson et al., 2006).

Colorectal cancer (CRC) constitutes the most frequent malignancy worldwide (Chan and Giovannucci, 2010). It has been described that one-third of human carcinoma might be associated with dietary habits, and lifestyle and dietary factors are known to be critical modulators of the development of human CRC (Chan and Giovannucci, 2010). Thus, one promising approach to reduce the incidence and improve the prognosis of CRC may be chemoprevention through diet. Flavanols EC, ECG and PB2 possess a well characterized in vitro antioxidant activity, and recent studies have shown that these catechins are effective free radical scavengers and interfere with the oxidative/antioxidative potential of hepatic (Coyle et al., 2008; Chen et al., 2002; Granado-Serrano et al., 2007, 2009b; Martin et al., 2008) and colonic cells (Rodríguez-Ramiro et al., 2011). Induction of antioxidant/detoxifying enzymes as well as glutathione (GSH) levels provide significant biological mechanisms for protection against toxic effects of endogenous reactive oxygen species (ROS) and exogenous carcinogens and/or their reactive intermediates (GranadoSerrano et al., 2007, 2009b; Martin et al., 2008, 2010; Rodríguez-Ramiro et al., 2011). Alternatively, the removal of preinitiated cells from damaged tissues through cell cycle arrest and apoptosis constitutes another possible mechanism in chemoprevention (Babich et al., 2005, 2006; Yang et al., 1998).

Different studies have shown that ECG, and to a much lesser degree EC and procyanidins, are potent chemopreventive agents inducing inhibition of cell growth, cell cycle dysregulation, and 
apoptosis in cells from human oral cavity (Babich et al., 2005), lung and colon (Baek et al., 2004; Gossé et al., 2005; Tan et al., 2000; Yang et al., 1998), and in head and neck squamous carcinoma cells (Lim et al., 2006). Furthermore, the preventive role of different tea catechins in human colorectal cancer is distinct depending on the flavanol (Baek et al., 2004). Accordingly, in HCT116 colon cancer cells epigallocatechin-3-gallate (EGCG) and ECG induce apoptosis, but not epigallocatechin (EGC) and EC (Baek et al., 2004). Thus, both EGCG and ECG have been suggested to play an important role in antitumorigenesis.

In addition, a differential toxicity of flavonoids in distinct cancer and normal cell lines, as well as in cancer cell lines with different growth rate has been reported. Babich et al. (Babich et al., 2005, 2006) have shown a more pronounced cytotoxic effect for EC, ECG and a theaflavin mixture in cancer human oral cavity cells than in their normal counterparts. Similarly, EGCG was the most potent catechin compared to EGC, ECG and EC at inhibiting cell growth in prostate cancer cell lines, showing that EGCG was particularly effective in the androgen-unresponsive DU145 cells, and especially in the androgen responsive LNCaP cells (Paschka et al., 1998). However, contrary to EGCG, little input has been directed to evaluate the potential effect on colon cancer cells by EC, ECG and PB2. It has been suggested that these compounds might exert beneficial and/or cytotoxic actions through their ability to stimulate the antioxidant defense system and their modulation of signal cascades (Baek et al., 2004; Granado-Serrano et al., 2007; Lim et al., 2006; Martin et al., 2008, 2010; Ramos, 2007; Rodríguez-Ramiro et al., 2011), but the exact mechanism of the differential effects of EC, ECG and PB2 is still unclear. Therefore, the study of the anticarcinogenic activity of flavanols in colonic cells may benefit from the use of two well-defined human CRC cell lines with different degrees of growth rate, namely Caco-2 and SW480. Caco-2 is a cell line widely used for biochemical and nutritional studies as a differentiated cell culture model of human colonocytes since they retain their morphology and most of their function in culture 
(Sambuy et al., 2005). SW480 cell line is moderately differentiated and invasive (Flatmark et al., 2004) and it is commonly used in metastasic studies (Yoon et al., 2008).

These two human colon carcinoma cell lines were used to study the mechanism of the anticancer activities of tea and cocoa phenolic components. Thus, cell viability and proliferation were assayed for the three flavanols. Later, in view of the results obtained, ROS production and intracellular GSH levels as markers for redox status were examined after ECG treatment. Also, the mechanisms underlying the biological effects of ECG in Caco-2 and SW480 cells and of PB2 in SW480 cells were investigated by evaluating key proteins in survival/proliferation pathways [AKT, and extracellular regulated kinase (ERK)], and in apoptotic cell death (caspase-3 and the Bcl-2 family members Bcl- $\mathrm{x}_{\mathrm{L}}, \mathrm{Bcl- \textrm {x } _ { \mathrm { S } }}$ and $\left.\mathrm{Bax}\right)$. 


\section{Materials and methods}

\section{Materials and chemicals}

EC, 2',7'-dichlorofluorescin diacetate (DCFH), o-phthalaldehyde (OPT), NADH, NADPH, LY294002 [2-(4-morpholinyl)-8-phenyl-1(4H)-benzopyran-4-one hydrochloride], PD98059 [2-(2amino-3-methoxyphenyl)-4H-1-benzopyran-4-one], gentamicin, penicillin $\mathrm{G}$ and streptomycin were purchased from Sigma Chemicals (Madrid, Spain). tert-butylhydroperoxide ( $t$-BOOH) was obtained from Panreac Quimica (Madrid, Spain). ECG and PB2 were from Extrasynthese (Genay, France). Cell proliferation ELISA 5-bromo-2'-deoxyuridine (BrdU) (colorimetric) assay kit was from Roche Diagnostics (Roche Molecular Biochemicals, Barcelona, Spain). GST fluorometric activity assay was purchased from Biovision (Deltaclon, Madrid, Spain). Anti-AKT and antiphospho-Ser473-AKT, as well as anti-ERK1/2 and anti-phospho-ERK1/2 recognizing phosphorylated Thr202/Thy204 of ERK1/2 and anti- $\beta$-actin were obtained from Cell Signalling Technology (Izasa, Madrid, Spain). Anti-Bclx, anti-Bax and anti-Bad were purchased from Santa Cruz Biotechnology (sc-634, sc-526, and sc-943, respectively). Caspase-3 substrate (Ac-DEVDAMC) was from BD Pharmingen (Madrid, Spain). Materials and chemicals for electrophoresis and the Bradford reagent were obtained from BioRad (Madrid, Spain). Cell culture dishes were from Falcon (Cajal, Madrid, Spain) and cell culture medium and fetal bovine serum (FBS) from Lonza (Madrid, Spain), respectively.

\section{Cell cultures and flavanol treatments}

Human Caco-2 and SW480 cells were grown in Dulbecco's Modified Eagle's Medium (DMEM) F12 medium, supplemented with $10 \%$ fetal bovine serum (FBS) and $50 \mathrm{mg} / \mathrm{L}$ of each antibiotic (gentamicin, penicillin and streptomycin). Cells were maintained at $37^{\circ} \mathrm{C}$ in a humidified atmosphere of $5 \% \mathrm{CO}_{2}$. SW480 cells were a gift from Prof. Alberto Muñoz (Instituto de Investigaciones Biomedicas “Alberto Sols”, CSIC, Madrid, Spain). 
Cells were changed to serum-free medium $24 \mathrm{~h}$ before the assay in order to avoid the influence of the growth factors contained in the FBS on the results. To study the cellular effect of the selected flavanols, different concentrations $(10-50 \mu \mathrm{M})$, diluted in serum-free culture medium, were added to the cell plates for $24 \mathrm{~h}$. In the experiments with the pharmacological inhibitors, cells were preincubated with $50 \mu \mathrm{M}$ PD98059 (a specific inhibitor of MAPK-ERK) or with $25 \mu \mathrm{M}$ of LY294002 (a specific inhibitor of AKT) for $1 \mathrm{~h}$ before and during ECG or PB2 treatments. At the end of the incubation period, cell cultures were processed according to the assay (see below).

\section{Cytotoxicity assays}

Cellular damage was evaluated by crystal violet assay (Granado-Serrano et al., 2007) and lactate dehydrogenase (LDH) leakage (Granado-Serrano et al., 2009a). For the crystal violet assay, cells were seeded $\left(2 \times 10^{5}\right.$ cells per well $)$ in 24 -well plates, grown for $20 \mathrm{~h}$ with the different treatments and then incubated with crystal violet $(0.2 \%$ in ethanol) for $20 \mathrm{~min}$. Plates were rinsed with water, allowed to dry, and $1 \%$ sodium dodecylsulfate (SDS) added. The absorbance of each well was measured at $570 \mathrm{~nm}$ using a microplate reader (Bio-Tek, Winooski, VT, USA). For LDH assay, the culture medium and the cells scraped in PBS were collected separately after the different treatments. Cells $\left(1.5 \times 10^{6}\right.$ cells $)$ were first sonicated to ensure breaking down the cell membrane to release the total amount of $\mathrm{LDH}$, centrifuged $(1000 \mathrm{~g}, 15 \mathrm{~min})$ to clear up the cell sample and the supernatants collected. To each well of 96-multiwell plates containing the sample $(10 \mu \mathrm{L}$ of culture medium or cell lysate), $200 \mu \mathrm{L}$ of a mixture comprising $5 \mathrm{mM}$ piruvate, $0.35 \mathrm{mM}$ NADH and $84 \mathrm{mM}$ Tris was added and immediately read at $340 \mathrm{~nm}$ in a microplate ELISA reader. LDH leakage was estimated as the ratio between the $\mathrm{LDH}$ activity in the culture medium and that of the whole cell content.

Cell proliferation assay (5-bromo-2'-deoxyuridine assay, BrdU) 
A colorimetric immunoassay (ELISA) was used for the quantification of cell proliferation. This method is based on the measurement of BrdU incorporation into genomic DNA during DNA synthesis of proliferating cells. Cells were seeded at low density $\left(10^{4}\right.$ cells per well) in 96-well plates, grown $20 \mathrm{~h}$ and labelled by the addition of BrdU for $4 \mathrm{~h}$. Then, the anti-BrdU antibody was added and the immune complexes were detected by the reaction with the substrate tetramethylbenzidine and quantified by measuring the absorbance at $620 \mathrm{~nm}$ in a microplate ELISA reader.

\section{Determination of reactive oxygen species (ROS) generation}

Cellular ROS generation was quantified by the DCFH assay using a microplate reader (GranadoSerrano et al., 2007). In brief, $5 \mu \mathrm{M}$ DCFH was added to the wells $\left(2 \times 10^{5}\right.$ cells per well) for 30 min at $37^{\circ} \mathrm{C}$. Then, cells were washed twice with PBS and serum-free medium or serum-free medium with flavanols were added per well. Multiwell plates were immediately measured at the fixed times in a fluorescent microplate reader (Bio-Tek, Winooski, VT) at excitation wavelength of $485 \mathrm{~nm}$ and emission wavelength of $530 \mathrm{~nm}$. After being oxidized by intracellular oxidants, DCFH becomes dichlorofluorescein (DCF) and emits fluorescence. By quantifying fluorescence, a fair estimation of the overall oxygen species generated under the different conditions was obtained.

\section{Determination of reduced glutathione}

Reduced glutathione (GSH) was quantified by the fluorimetric assay of Hissin and Hilf (Hissin and Hilf, 1976). The method is based on the reaction of reduced glutathione with OPT at $\mathrm{pH}$ 8.0. In brief, after the different treatments cells were detached and homogenized by ultrasound with $5 \%$ trichloroacetic acid and $2 \mathrm{mM}$ EDTA. Following centrifugation of cells at $7000 \mathrm{~g}$ for $30 \mathrm{~min}$ at $4^{\circ} \mathrm{C}, 50 \mu \mathrm{L}$ of the supernatant were mixed with $1 \mathrm{M} \mathrm{NaOH}, 0.1 \mathrm{M}$ sodium phosphate buffer and 10 
$\mu \mathrm{L}$ OPT $(10 \mathrm{mg} / \mathrm{mL})$. Fluorescence was measured at excitation wavelength of $340 \mathrm{~nm}$ and emission wavelength of $460 \mathrm{~nm}$. The results of samples were referred to those of a standard curve of GSH.

Determination of glutathione peroxidase (GPx), glutathione reductase $(G R)$ and glutathione-Stransferase (GST) activity

For the assay of the GPx and GR activity, treated cells were suspended in PBS and centrifuged at $300 \mathrm{~g}$ for $5 \mathrm{~min}$ to pellet cells. Cell pellets were resuspended in $20 \mathrm{mM}$ Tris, $5 \mathrm{mM}$ EDTA and 0.5 $\mathrm{mM}$ mercaptoethanol, sonicated and centrifuged at $3000 \mathrm{~g}$ for $15 \mathrm{~min}$. Enzyme activities were measured in the supernatants. Determination of GPx activity is based on the oxidation of GSH by GPx, using tert-butylhydroperoxide $(t-\mathrm{BOOH})$ as a substrate, coupled to the disappearance of NADPH by GR (Alia et al., 2005). GR activity was determined by following the decrease in absorbance due to the oxidation of NADPH utilized in the reduction of oxidized glutathione (Alia et al., 2005). Analysis of GST was carried out by the commercial kit GST fluorometric activity assay. The assay utilizes monochlorobimane (MCB) as an artificial substrate and glutathione to determine total GST activity. GST catalyses the MCB-glutathione reactions and the fluorescence levels are proportional to the amount of GST present in the reaction medium. A fluorescent microplate reader at an excitation wavelength of $380 \mathrm{~nm}$ and an emission wavelength of $460 \mathrm{~nm}$ was used. The activity obtained in $\mathrm{mU} / \mathrm{mg}$ protein was expressed as percent of control values. Protein was measured by using the Bradford reagent.

\section{Fluorometric analysis of caspase-3 activity}

Caspase-3 activity was measured as previously described (Granado-Serrano et al., 2006). Detached cells were collected by centrifugation at $2500 \mathrm{~g}$ for $5 \mathrm{~min}$ at $4^{\circ} \mathrm{C}$. Attached cells were scrapped off in PBS and pelleted by centrifugation at $4000 \mathrm{~g}$ for $10 \mathrm{~min}$. Cells were pooled and lysed at $4^{\circ} \mathrm{C}$ in 
a buffer containing $5 \mathrm{mM}$ Tris (pH 8), $20 \mathrm{mM}$ EDTA and 0.5\% Triton-X100. Later, lysates were clarified by centrifugation at $13000 \mathrm{~g}$ for $10 \mathrm{~min}$. The reaction mixture contained $20 \mathrm{mM}$ HEPES (pH 7), 10\% glycerol, $2 \mathrm{mM}$ dithiothreitol (DTT), $30 \mu \mathrm{g}$ protein/condition and $20 \mu \mathrm{M}$ Ac-DEVDAMC (N-acetyl-Asp-Glu-Val-Asp-7-amino-4-methylcoumarin) as substrate. Enzymatic activity was determined by measuring fluorescence at an excitation wavelength of $380 \mathrm{~nm}$ and an emission wavelength of $440 \mathrm{~nm}$.

\section{Preparation of total cell lysates for Western blotting}

To detect Bclx, Bax, Bad, AKT, phospho-AKT, ERK1/2 and phospho-ERK1/2, cells were lysed at $4^{\circ} \mathrm{C}$ in a buffer containing $25 \mathrm{mM}$ HEPES (pH 7.5), $0.3 \mathrm{M} \mathrm{NaCl}, 1.5 \mathrm{mM} \mathrm{MgCl}, 0.2 \mathrm{mM}$ EDTA, $0.5 \mathrm{mM}$ DTT, $0.1 \%$ Triton X-100, $200 \mathrm{mM} \beta$-glycerolphosphate, $0.1 \mathrm{mM} \mathrm{Na} \mathrm{VO}_{4}, 2 \mu \mathrm{g} / \mathrm{mL}$ leupeptin and $1 \mathrm{mM}$ phenylmethylsulfonyl fluoride. The supernatants were collected, assayed for protein concentration by using the Bio-Rad (Madrid, Spain) protein assay kit according to the manufacture's specifications, aliquoted and stored at $-80^{\circ} \mathrm{C}$ until used for Western blot analyses.

\section{Western blot analysis}

Equal amounts of proteins $(100 \mu \mathrm{g})$ were separated by SDS-PAGE and transferred to polyvinylidene difluoride filters (Millipore, Madrid, Spain). Membranes were probed with the corresponding primary antibody followed by incubation with peroxide-conjugated anti-rabbit immunoglobulin (GE Healthcare, Madrid, Spain). Blots were developed with the ECL system (GE Healthcare, Madrid, Spain). Normalization of Western blot was ensured by $\beta$-actin and band quantification was carried out with a scanner (HP Scanjet G2710, HP, Madrid, Spain) and the Scion Image software (Scion Corporation, MD, USA).

\section{Statistics}


All experiments were performed in triplicate or quadruplicate with 2-6 separate samples each $(\mathrm{n}=$ 4-12), as indicated in the legends to figures, and the results were presented as mean \pm SD. Prior to statistical analysis, data were tested for homogeneity of variances by the test of Levene; for multiple comparisons, one-way ANOVA was followed by the Bonferroni test when variances were homogeneous or by the Tamhane test when variances were not homogeneous. Different letters on top of the bars indicate significantly different results obtained for the corresponding analyzed parameter. $P<0.05$ was considered significant. A SPSS version 17.0 program has been used. 


\section{Results}

Effect of flavanols on Caco-2 and SW480 cell viability.

To determine the potential effects on cell viability of the selected flavanols in both human colon cancer cell lines (Caco-2 and SW480), cells were exposed to a range of concentrations $(0-50 \mu \mathrm{M})$ of phenolic compounds for $24 \mathrm{~h}$.

Treatment of Caco- 2 cells for $24 \mathrm{~h}$ with any of the three flavanols evoked no changes in cell viability, as determined by the crystal violet assay, indicating that the concentrations selected for the study did not damage cell integrity during the period of incubation (Figure 1A). Similarly, treatment with EC did not induce SW480 cell damage, whereas ECG decreased cell viability at concentrations higher than $20 \mu \mathrm{M}$ (Figure 1B). In addition, 20-50 $\mu \mathrm{M}$ PB2 caused an increase in cell viability after $24 \mathrm{~h}$ of treatment as compared to untreated SW480 cells, which could indicate an augmented cell proliferation (Figure 1B).

\section{Effect of flavanols on Caco-2 and SW480 cell proliferation.}

To test whether cell proliferation was affected by the selected flavanols, Caco-2 and SW480 cells were incubated with the different concentrations for $24 \mathrm{~h}$.

Treatment of Caco-2 with any of the three flavanols did not affect cell growth, similarly to what was observed in SW480 cells after the incubation with EC, indicating no impairment of cell proliferative machinery and preservation of a regular cell cycle (Figure 2). On the other hand, in SW480 cells 24 h-incubation with PB2 showed an increase in cell proliferation, and ECG treatment led to a decrease in cell proliferation (Figure 2B), in agreement with crystal violet results (Figure 1).

Given that ECG was the only flavanol that provoked a potential anticarcinogenic effect by inducing cytotoxicity and decreasing cell proliferation in SW480 cells, this was the flavanol selected for studying the effects on apoptosis and survival/proliferation pathways. In addition, PB2 
was chosen to evaluate its effect on key proteins of apoptosis and survival/proliferation pathways in SW480 cells since it promoted cell proliferation.

Effect of ECG on Caco-2 and SW480 LDH leakage.

In view of the different effect observed for ECG on cell viability and proliferation depending on the colon cancer cell line, the potential necrotic effect of this flavanol was tested in Caco-2 and SW480 cells by measuring the LDH leakage after $24 \mathrm{~h}$ of incubation with the different concentrations. As shown in Figure 3A, ECG did not induce any cell damage at the concentrations assayed (10-50 $\mu \mathrm{M})$ in Caco-2 cells. However, ECG provoked a slight injury in the membrane of the SW480 cells at concentrations higher than $20 \mu \mathrm{M}$ (Figure 3B). Thus, it could be suggested that Caco-2 cells appeared to be less susceptible to the cytotoxic effect of ECG than SW480 cells after $24 \mathrm{~h}$ of incubation with this flavanol.

\section{Effect of ECG on ROS production and GSH concentration.}

Since flavanols can affect the cellular redox status, we next evaluated ROS generation and reduced glutathione (GSH) levels after ECG treatment (24 h) in Caco-2 and SW480 cells.

ECG evoked a significant reduction of the cellular ROS generation, showing lower levels than control cells in both cell lines (Figures 3C and 3D). On the other hand, ECG at the highest concentration tested $(50 \mu \mathrm{M})$ evoked an increase in the levels of GSH in Caco-2 cells (Figure 3E), whereas in SW480 cells ECG provoked a dose-dependant reduction of the intracellular GSH content (Figure 3F). Thus, these results show that ECG evokes a distinct reaction on GSH levels depending on the colon cancer cell line.

Effect of ECG on the activity of antioxidant/detoxification enzymes in SW480 cells. 
To continue the study of the potential anticarcinogenic effect of ECG, the cellular antioxidant enzyme system, which is essential for maintaining the adequate cellular redox status (Masella et al., 2005; Moon et al., 2006), was evaluated by analyzing the activity of different antioxidant/detoxifying enzymes (GPx, GR and GST). As shown in Figure 4, ECG evoked no changes in activity of GR and GST (Figures 4B and 4C), whereas treatment with 20-50 $\mu \mathrm{M}$ ECG induced an increase in GPx activity (Figure 4A). This effect on GPx could be related to the decreased GSH content exhibited by this flavanol in SW480 cells.

\section{Effect of ECG on apoptosis induction in Caco-2 and SW480 cells.}

Since redox imbalance might lead to apoptotic cell death, the enzymatic activity of caspase-3, which is a crucial effector in the terminal or execution phase of the apoptotic pathway, was examined in SW480 cells treated with ECG. As shown in Figure 5A, the presence of 30-50 $\mu \mathrm{M}$ ECG induced the activation of caspase-3, which was coincident with the decreased cell viability, proliferation and intracellular GSH content.

In addition, an imbalance in the expression of anti- and pro-apoptotic proteins is one of the major mechanisms underlying the ultimate fate of cells in the survival/apoptotic process (GranadoSerrano et al., 2006). It is known that different members of the $b c l-2$ gene family regulate survival or death in mammalian cells (Granado-Serrano et al., 2006; Ramos, 2007). Thus, the possible modulation by ECG on the expression of anti- or proapoptotic members of this protein family (Bcl-x, Bad and Bax, respectively) was studied in Caco-2 and SW480 cells. ECG did not induce a significant effect on the levels of $\mathrm{Bcl}-\mathrm{x}_{\mathrm{L}}$ antiapoptotic protein or proapoptotic proteins (Bax and Bad) in Caco-2 cells (Figures 5B and 5C). Also consistent with all the above, treatment of SW480 cells with ECG for $24 \mathrm{~h}$ altered the balance among anti- and pro-apoptotic Bcl-2 family members (Figures 5D and 5E). 
$\mathrm{Bcl}-\mathrm{x}_{\mathrm{L}}$ has been proposed to be a caspase substrate, and the product of $\mathrm{Bcl}-\mathrm{x}_{\mathrm{L}}$ cleavage, $\mathrm{Bcl}-\mathrm{x}_{\mathrm{S}}$, has a proapoptotic function. This proteolytic fragment $\left(\mathrm{Bcl}-\mathrm{x}_{\mathrm{S}}\right)$ was detected when SW480 cells were incubated for $24 \mathrm{~h}$ with ECG, and the levels were higher at 30-50 $\mu \mathrm{M}$ ECG concentrations as compared to control cells (Figures 5D and 5E). ECG also induced an enhancement of Bad levels from $20 \mu \mathrm{M}$ up to $50 \mu \mathrm{M}$, which showed the maximum values with 40 and $50 \mu \mathrm{M}$ ECG (Figures 5D and 5E). Additionally, Bax was not affected by ECG incubation in SW480 cells.

Effect of ECG on the survival/proliferation in Caco-2 and SW480 cells.

PI3K/AKT and ERK-MAPK play an important role in cell survival/proliferation, and can be modulated by polyphenols (Ramos, 2007). To investigate whether ECG treatment in Caco-2 cells was able to activate key proteins related to cellular survival/proliferation, PI3K/AKT and ERKMAPK were analyzed. Figures $6 \mathrm{~A}$ and $6 \mathrm{~B}$ illustrate that a $24 \mathrm{~h}$ treatment with ECG did not show a significant effect on the levels phosphorylated AKT and ERK in Caco-2 cells. Likewise, there was no difference in the total levels of AKT and ERK. These results, together with the lack of effect on cell damage and on cell proliferation reported above, suggest that $24 \mathrm{~h}$ of treatment with ECG has neither a prominent cytotoxic effect nor a proliferative/survival action in Caco-2 cells.

Similarly, it was investigated whether ECG treatment was able to regulate key proteins of these intracellular signaling cascades in SW480 cells. ECG treatment induced a decrease in AKT phosphorylated levels and a strong activation of ERK at concentrations higher than $20 \mu \mathrm{M}$ (Figures 6C and 6D). The protein expression levels of total AKT and ERK were not modified by ECG treatment. Therefore, it could be suggested that ECG triggers apoptosis by modulating Bcl-2 family members, i.e. enhancing the levels of pro-apoptotic proteins (Bad) and decreasing the Bcl$\mathrm{x}_{\mathrm{L}} / \mathrm{Bcl}-\mathrm{x}_{\mathrm{S}}$ ratio, as well as by the activation of ERK and the inhibition of AKT.

Effect of PB2 on the survival/proliferation in SW480 cells. 
In view of the proliferative effect induced by PB2 in SW480 cells, it was studied whether this flavanol was able to modulate the expression of anti- and pro-apoptotic Bcl-2 proteins and/or to activate key proteins related to cellular survival/proliferation (AKT and ERK). To this end, SW480 cells were exposed to PB2 for $24 \mathrm{~h}$ and protein specific immunoblots were then performed. Treatment with PB2 did not modify the levels of the anti- $\left(\mathrm{Bcl}-\mathrm{x}_{\mathrm{L}}\right)$ and pro-apoptotic (Bax and Bad) proteins and induced the phosphorylation of AKT and ERK with concentrations higher than $10 \mu \mathrm{M}$ after $24 \mathrm{~h}$ of treatment (Figure 7). Likewise, there was no difference in the total levels of AKT and ERK. These results, together with the effect on cell damage and cell proliferation reported above, suggest that $24 \mathrm{~h}$ of treatment with PB2 has a prominent proliferative/survival action in SW480 cells.

Effect of ECG and PB2 on the AKT and ERK modulation in Caco-2 and SW480 cells. To address the role of AKT/PI-3-kinase and ERK in ECG-induced apoptotic and PB2-stimulated survival/proliferation effects, selective inhibitors of these proteins were used and the result on cell viability was determined. The concentration selected for these analyses was the lowest dose that showed a prominent effect on the inhibition or activation of both proteins, i.e: $30 \mu \mathrm{M}$. LY294002 or PD98059 alone did not have any effect on cell viability (data not shown).

Treatment of Caco-2 cells with PD98059 followed by the addition of ECG or PB2 (30 $\mu \mathrm{M})$ showed a cytotoxic effect, whereas treatment with the AKT selective inhibitor did not alter cell viability in Caco-2 cells incubated with ECG or PB2 (Figures 8A and 8B). On the other hand, treatment of SW480 cells with the selective inhibitor LY294002 followed by the addition of ECG markedly increased cell damage, whereas incubation with ECG in the presence of PD98059 showed comparable values to controls (Figure 8C). In addition, in SW480 cells, the treatment with the selective inhibitors LY294002 or PD98059 followed by the addition of PB2 returned the cell viability to similar levels of those of control cells (Figure 8D). 
Taken all together, it could be suggested that cellular survival seemed to depend on the induction of the ERK pathway in Caco-2 cells, whereas in SW480 cells the modulation of both AKT/PI-3kinase and ERK signaling cascades seemed to contribute to the fate of the cells. 


\section{Discussion}

In this study, we evaluated the anticarcinogenic properties of three catechins (EC, ECG and PB2) with different degree of polymerization and galloylation in two human colon cancer cells with distinct degree of differentiation, according to their grade of infiltration or metastasis (Flatmark et al., 2004). These flavanols have demonstrated in different extension a potential anticarcinogenic effect in distinct cell lines, such as oral cavity (Babich et al., 2005, 2006), prostate (Chung et al., 2001), hepatic (Granado-Serrano et al., 2009a), neck squamous (Lim et al., 2006) and colon (Baek et al., 2004; Gossé et al., 2005; Rodríguez-Ramiro et al., 2011; Tan et al., 2000; Yang et al., 1998). In addition, the degree of differentiation among cells from the same tissue seems to be important for such selective cytotoxicity (Babich et al., 2005, 2006; Yang et al., 1998). Our results revealed that EC, ECG and PB2 induce a differential cellular response depending on their chemical structure and the proliferative rate of the colon cancer cell line.

The cytotoxic effects of the three flavanols on Caco-2 cells and of EC on SW480 cells are irrelevant as demonstrated by the lack of variations in cell viability and proliferation, as previously reported for these dietary phenolic compounds in other cell cultures prostate (Chung et al., 2001), oral (Babich et al., 2005), lung (Yang et al., 1998), and colon (Tan et al., 2000; Yang et al., 1998) cancer cells. Accordingly, EC induces cell survival through the activation of signaling pathways (Granado-Serrano et al., 2009a) and protects liver-derived cells from an oxidative stress by returning the antioxidant defense system to a steady-state activity (Granado-Serrano et al., 2009b; Martin et al., 2008). Interestingly, PB2 seems to slightly promote proliferation of SW480 cells. Similarly it has been reported that EC increased cell proliferation in colon carcinoma LoVo cells (Tan et al., 2000).

ECG displayed a differential growth inhibitory effect on the two human colon cancer cell lines, inducing a decrease in cell proliferation in the less differentiated SW480 cells, but not in Caco-2 cells, which are akin to colonocytes. In line with this, a different susceptibility has been described 
for HCT116 and HT29 colon cancer cells in comparison to Caco-2 cells after their incubation with propolis ethanol extracts, showing a more remarkable growth decrease in HCT116 and HT29 cells with a high proliferation rate (Ishihara et al., 2009). Similarly, the cytotoxic effect of EC and ECG was more pronounced in human cancer oral cavity cells than in their normal counterparts (Babich et al., 2005).

ECG differs from EC only by the presence of a gallic acid molecule on the B-ring, although ECG seems to be more biologically active as an antiproliferative agent than EC and procyanidins (Babich et al., 2005; Rodríguez-Ramiro et al., 2011; Tan et al., 2000). Thus, ECG showed a higher growth suppression and apoptosis induction potential than EC in prostate cancer cells (Chung et al., 2001). In this regard, the influence of catechin chemical structure on antiproliferative activity has to be considered. Research with different cell lines has shown that galloylation of catechins could be an important chemical characteristic (Fiuza et al., 2004; Lizarraga et al., 2008). Thus, in HT-29 cells treated with a procyanidin-rich grape extract, the fractions most efficient inducing apoptosis were those with the highest percentage of galloylation (Lizarraga et al., 2008). ROS are highly reactive metabolites generated during normal cell metabolism and could act as signaling factors. There is growing evidence that intracellular ROS may be directly related to the depletion of GSH. Our study shows a decrease of ROS production induced by ECG in both cell lines together with an induction of GSH levels by ECG in Caco-2 cells and a reduction in SW480 cells. There is evidence showing that ECG possesses a high antioxidant activity and decreases the steady-state generation of ROS in Caco-2 cells without affecting cell viability or intracellular GSH levels (Rodríguez-Ramiro et al., 2011). All these effects have been related to the prevention or delay of appearance of conditions that cause oxidative stress in the cell (Azam et al., 2004; Chen et al., 2002; Rodríguez-Ramiro et al., 2011) and may also reflect the ability of ECG to modulate the cellular antioxidant defenses (Rodríguez-Ramiro et al., 2011). 
Interestingly, ECG also reduced ROS generation in SW480 cells, but this occurs together with a dramatic depletion of GSH intracellular levels and a diminished cell viability and proliferation. In this regard, other studies have reported a decreased steady-state generation of ROS induced by EGCG and ECG, which has been related to a suppression of ONOO- formation and/or modulation of nitrite levels by both catechins due to their high antioxidant capacity (Coyle et al., 2008). Moreover, it should be highlighted that the loss of cellular GSH redox status seems to be an important player in apoptotic signaling (Granado-Serrano et al., 2009b; Rodríguez-Ramiro et al., 2010).

Flavanols have been recently shown to provide a parallel protection by enhancing the activity of a number of protective GSH-dependent enzymes (Granado-Serrano et al., 2009b; Martin et al., 2010; Masella et al., 2005; Moon et al., 2006), which seem to play an essential role in cancer prevention (Moon et al., 2006). In line with this potential mechanism of action, it has been shown that in Caco-2 cells PB2 increases the activity of antioxidant/detoxification enzymes, ECG increases the activity of GPx and EC does not affect to any activity of the protective GSHdependent enzymes (Rodríguez-Ramiro et al., 2010, 2011). In the present study ECG evokes a substantial increase in GPx activity without altering GR and GST activities in SW480 cells. This outcome indicates that ECG-treated SW480 cells are under oxidative stress conditions (Alia et al., 2005), which could also be connected with the depletion of GSH levels and cell death.

ECG-induced apoptosis has already been demonstrated in colon (Baek et al., 2004; Tan et al., 2000; Yang et al., 1998) and in lung (Yang et al., 1998) cancer cells. ECG also induced caspase-3 activity, and DNA fragmentation, indicative of apoptosis in human oral cancer cells (Babich et al., 2005). However, the modes of action underlying these effects have not been clearly defined. As our results showed, expression of $\mathrm{Bcl}-\mathrm{x}_{\mathrm{L}}, \mathrm{Bcl}-\mathrm{x}_{\mathrm{S}}$, Bad and Bax could be differently regulated by ECG suggesting that the balance in the expression of these proteins might be involved in the control of the apoptotic process (Granado-Serrano et al., 2006, 2007). ECG decreased the Bcl- 
$\mathrm{x}_{\mathrm{L}} / \mathrm{Bcl}-\mathrm{x}_{\mathrm{S}}$ ratio in $\mathrm{SW} 480$ cells; thus, regulation of $\mathrm{Bcl}-\mathrm{x}_{\mathrm{L}}$ protein levels seems to be, at least in part, caspase-dependent in SW480 cells, which agrees with previous results in hepatic cells treated with quercetin (Granado-Serrano et al., 2006).

On the contrary, in Caco-2 cells the expression levels of Bax and Bad (proapoptotic), as well as Bcl- $\mathrm{x}_{\mathrm{L}}$ (antiapoptotic) remained unchanged after treatment with ECG; moreover, the proapoptotic $\mathrm{Bcl}-\mathrm{x}_{\mathrm{S}}$ resulting from $\mathrm{Bcl}-\mathrm{x}$ cleavage as an indication of apoptotic cell death was not detected. Similarly, unchanged levels of Bcl-2, Bcl- $\mathrm{x}_{\mathrm{L}}$, and Bax have been described in a study carried out with EGCG in prostatic cancer cells (Chung et al., 2001). These results suggest that Bcl-2 proteins might not be directly involved in the molecular signaling pathways activated by ECG in Caco-2 cells.

AKT promotes cell survival by inhibiting apoptosis, and its phosphorylation has been considered a critical factor in the progression of CRC (Pan et al., 2011). Similarly, ERK is also required for survival (Nicholson and Anderson, 2002), but diverse studies have suggested that the role of ERK in determining the fate of cells (survival or death) is cell type specific (Zhou et al., 2005). ECG induced an enhancement of p-ERK and a diminution of p-AKT levels in SW480 cells, whereas it did not alter the levels of p-AKT or p-ERK in Caco-2 cells. In this regard, it has been reported that catechins differently affect ERK activation in HT-29 cells (Jung et al., 2011). Thus, ECG, as well as EC and EGC, did not affect p-ERK levels at a concentration of $30 \mu \mathrm{M}$ in HT-29 cells (Jung et al., 2011). Similarly, other natural compounds enhanced p-ERK levels and decreased p-AKT values leading to apoptosis in diverse colon cancer cells (Auyeung et al., 2010; Hyun et al., 2009). In line with this, the blockage of ERK by a pharmacological inhibitor in SW40 cells treated with ECG led to the recovery of cell viability, whereas the decline of AKT by a specific inhibitor provoked an increase in the number of dead cells.

PB2 increased proliferation as well as p-AKT and p-ERK levels in SW480 cells. This proliferative effect could be related to the activation of key proteins in survival/proliferation pathways, since 
the selective blockage of the PI-3-kinase and ERK pathways by pharmacological inhibitors suppressed PB2-induced proliferation in SW480 cells, as previously shown for EC (GranadoSerrano et al., 2007). In line with this, it has been recently demonstrated that PB2 exerted a protective role against an induced oxidative stress in Caco-2 cells (Rodríguez-Ramiro et al., 2010, 2011). In addition, cellular survival seemed to depend on the induction of the ERK pathway in Caco-2 cells, since incubation with the inhibitor PD98059 in the presence of PB2 reduced the number of viable cells, which was not affected after the blockage of the AKT/PI3K pathway. However, it should be highlighted that apoptosis induction by highly oligomeric procyanidins has been described (degree of polymerization 4 or superior) (Gossé et al., 2005).

Although serum bioavailability of flavanols is low, daily intakes as high as $18-50 \mathrm{mg}$ /day have been reported (Manach et al., 2005), and steady-state concentrations up to $35 \mu \mathrm{M}$ of EC have been observed in rat serum $1 \mathrm{~h}$ after oral administration of the flavanol (Baba et al., 2001). In addition, previous work (Aura et al., 2005) suggested that a major portion of ingested polyphenols survive digestion in the upper gastrointestinal tract (GIT) and reach the colon, where they could be subjected to fermentation by colonic microflora. This has been confirmed in human ileostomy patients (Karle et al., 2006). Thus, considering the high catechin content of green tea and cocoa, colonic cells could be exposed to flavanols levels similar to those tested in the present study. Therefore, our studies show for the first time that ECG at a physiological relevant dosage inhibited the growth and induced apoptosis in colon SW480 cells, but not in Caco-2 cells. On the contrary, PB2 promoted cell growth of SW480 cells by activating survival/proliferation pathways. However, before proposing a flavanol for therapeutic use further studies are needed (probing the lack of toxicity on the primary healthy colon cells, etc.).

In summary, EC, ECG and PB2 exert a different response depending on their distinct chemical structure and the different degree of cell differentiation: ranging from no effect of any of the tested flavanols on Caco-2 cells to a proapoptotic effect of ECG in SW480 cells (feasibility interpreted as 
a chemopreventive action), to a survival/proliferative effect of PB2 on this cell line, which is an undesirable effect in cancer chemoprevention. Thus, these results highlight the importance of a holistic approach to the study of the biological effects of phytochemicals and call for caution on the conclusions derived from their studies. 


\section{Acknowledgements}

This work was supported by the grants AGL2007-64042, 200870I198 and CSD2007-00063 from the Spanish Ministry of Science and Innovation (MICINN). I. Rodríguez-Ramiro is a fellow of the JAE predoctoral program of Consejo Superior de Investigaciones Científicas (CSIC). 


\section{References}

Alia, M., Ramos, S., Mateos, R., Bravo, L., Goya, L., 2005. Response of the antioxidant defense system to tert-butyl hydroperoxide and hydrogen peroxide in a human hepatoma cell line (HepG2). J. Biochem. Mol. Toxicol. 19, 119-128.

Aura, A.M., Martin-Lopez, P., O’Leary, K.A., Williamson, G., Oksman-Caldentey, M., Poutanen, K., Santos-Buelga, C., 2005. In vitro metabolism of anthocyanins by human gut microflora. Eur. J. Nutr. 44, 1-10.

Auyeung, K.K., Mok, N.L., Wong, C.M., Ko, J.K., 2010. Astragalus saponins modulate mTOR and ERK signaling to promote apoptosis through the extrinsic pathway in HT-29 colon cancer cells. Int. J. Mol. Med. 26, 341-349.

Azam, S., Hadi, N., Khan, N., Hadi, S., 2004. Prooxidant property of green tea polyphenols epicatechin and epigallocatechin-3-gallate: implications for anticancer properties. Toxicol. in Vitro 18, 555-561.

Baba, S., Osakabe, N., Natsume, N., Muto, Y., Takizawa, T., Terao, J., 2001. In vivo comparison of the bioavailability of (+)-catechin, (-)-epicatechin and their mixture in orally administered rats. J. Nutr. 131, 2885-2891.

Babich, H., Krupka, M., Nissim, H., Zuckerbraun, H., 2005. Differential in vitro cytotoxicity of ()-epicatechin gallate (ECG) to cancer and normal cells from the human oral cavity. Toxicol. in Vitro 19, 231-242.

Babich, H., Pinsky, S., Muskin, E., Zuckerbraun, H., 2006. In vitro cytotoxicity of a theaflavin mixture from black tea to malignant, immortalized, and normal cells from the human oral cavity. Toxicol. in Vitro 20, 677-688.

Baek, S.J., Kim, J.S., Jackson, F.R., Eling, T.E., McEntee, M.F., Lee, S.H., 2004. Epicatechin gallate-induced expression of NAG-1 is associated with growth inhibition and apoptosis in colon cancer cells. Carcinogenesis 25, 2425-2432. 
Coyle, C.H., Philips, B.J., Morrisroe, S.N., Chancellor, M.B., Yoshimura, N., 2008. Antioxidant effects of green tea and its polyphenols on bladder cells. Life Sci. 83, 12-18.

Chan, A.T., Giovannucci, E.L., 2010. Primary prevention of colorectal cancer. Gastroenterol. $138,2029-2043$.

Chen, L., Yang, X., Jiao, H., Zhao, B., 2002. Tea catechins protect against lead-induced cytotoxicity, lipid peroxidation, and membrane fluidity in HepG2 cells. Toxicol. Sci. 69, 149-156.

Chung, L., Cheung, T., Kong, S., Fung, K., Choy, Y., Chan, Z., Kwok, T., 2001. Induction of apoptosis by green tea catechins in human prostate cancer DU145 cells. Life Sci. 68, 1207-1214.

Fiuza, S.M., Gomes, C., Teixeira, L.J., Girao da Cruz, M.T., Cordeiro, M.N., Milhazes, N., Borges, F., Marques, M.P., 2004. Phenolic acid derivatives with potential anticancer properties-a structure activity relationship study. Part I: methyl, propyl and octyl esters of caffeic and gallic acids. Bioorg. Med. Chem. 12, 3581-3589.

Flatmark, K., Maelandsmo, G.M., Martinsen, M., Rasmussen, H., Fodstad, O., 2004. Twelve colorectal cancer cell lines exhibit highly variable growth and metastatic capacities in an orthotopic model in nude mice. Eur. J. Cancer 40, 1593-1598.

Gossé, F., Guyot, S., Roussi, S., Lobstein, A., Fischer, B., Seiler, N., Raul, F., 2005.

Chemopreventive properties of apple procyanidins on human colon cancer-derived metastatic SW620 cells and in a rat model of colon carcinogenesis. Carcinogenesis 26, 1291-1295.

Granado-Serrano, A., Martín, M., Bravo, L., Goya, L., Ramos, S., 2006. Quercetin induces apoptosis via caspase activation, regulation of Bcl-2, and inhibition of PI-3-Kinase/Akt and ERK pathways in a human hepatoma cell line (HepG2). J. Nutr. 136, 2715-2721. 
Granado-Serrano, A., Martin, M., Goya, L., Bravo, L., Ramos, S., 2009a. Time-course regulation of survival pathways by epicatechin on HepG2 cells. J. Nutr. Biochem. 20, 115-124.

Granado-Serrano, A., Martin, M., Izquierdo-Pulido, M., Goya, L., Bravo, L., Ramos, S., 2007. Molecular mechanisms of (-)-epicatechin and chlorogenic acid on the regulation of the apoptotic and survival/proliferation pathways in a human hepatoma cell line. J. Agric. Food Chem. 55, 2020-2027.

Granado-Serrano, A.B., Martin, M.A., Bravo, L., Goya, L., Ramos, S., 2009b. A diet rich in cocoa attenuates $N$-nitrosodiethylamine-induced liver injury in rats. Food Chem. Toxicol. 47, 2499-2506.

Hissin, P., Hilf, R., 1976. A fluorometric method for determination of oxidised and reduced glutathione in tissues. Anal. Biochem. 74, 214-226.

Hyun, J.-H., Kim, S.-C., Kang, J.-I., Kim, M.-K., Boo, H.-J., Kwon, J.-M., Koh, Y.-S., Hyun, J.W., Park, D.-B., Yoo, E.-S., Kang, H.-K., 2009. Apoptosis inducing activity of fucoidan in HCT-15 colon carcinoma cells. Biol. Pharm. Bull. 32, 1760-1764.

Ishihara, M., Naoi, K., Hashita, M., Itoh, Y., Suzui, M., 2009. Growth inhibitory activity of ethanol extracts of Chinese and Bazilian propolis in four human colon carcinoma cell lines. Oncol. Rep. 22, 349-354.

Jung, Y.D., Kim, M.S., Shin, B.A., Chay, K.O., Ahn, B.W., Liu, W., Bucana, C.D., Gallick, G.E., Ellis, L.M., 2011. EGCG, a major component of green tea, inhibits tumour growth by inhibiting VEGF induction in human colon carcinoma cells. Brit. J. Cancer 84, 844-850.

Karle, K., Kraus, M., Scheppach, W., Ackerman, M., Ridder, F., Richling, E., 2006. Studies on apple and blueberry fruits constituents: do polyphenols reach the colon after ingestion? Mol. Nutr. Food Res. 50, 418-423.

Lamuela-Raventós, R., Romero-Pérez, A., Andrés-Lacueva, C., Tornero, A., 2005. Review: health effects of cocoa flavonoids. Food Sci. Technol. Int. 11, 159-176. 
Lim, Y.C., Lee, S.H., Song, M.H., Yamaguchi, K., Yoon, J.H., Choi, E.C., Baek, S.J., 2006. Growth inhibition and apoptosis by (-)-epicatechin gallate are mediated by cyclin D1 suppression in head and neck squamous carcinoma cells. Eur. J. Cancer 42, 3260-3266.

Lizarraga, D., Lozano, C., Briedé, J.J., van Delft, J.H., Touriño, S., Centelles, J.J., Torres, J.L., Cascante, M., 2008. The importance of polymerization and galloylation for the antiproliferative properties of procyanidin-rich natural extracts. FEBS J. 274, 48024811.

Manach, C., Williamson, G., Morand, C., Scalbert, A., Rémésy, C., 2005. Bioavailability and bioefficacy of polyphenols in humans. I. Review of 97 bioavailability studies. Am. J. Clin. Nutr. 81(suppl), 230S-242S.

Martin, M.A., Granado-Serrano, A.B., Ramos, S., Izquierdo-Pulido, M., Bravo, L., Goya, L., 2010. Cocoa flavonoids up-regulate antioxidant enzyme activity via the ERK1/2 pathway to protect against oxidative stress-induced apoptosis in HepG2 cells. J. Nutr. Biochem. 21, 196-205.

Martin, M.A., Ramos, S., Mateos, R., Granado-Serrano, A.B., Izquierdo-Pulido, M., Bravo, L., Goya, L., 2008. Protection of human HepG2 cells against oxidative stress by cocoa phenolic extract. J. Agric. Food Chem. 56, 7765-7772.

Masella, R., Di Benedetto, R., Vari, R., Filesi, C., Giovannini, C., 2005. Novel mechanisms of natural antioxidant compounds in biological systems: involvement of glutathione-related enzymes. J. Nutr. Biochem. 16, 577-586.

Moon, Y.J., Wang, X., Morris, M.E., 2006. Dietary flavonoids: effects on xenobiotic and carcinogen metabolism. Toxicol. in Vitro 20, 187-210.

Nicholson, K., Anderson, N., 2002. The protein kinase B/Akt signalling pathway in human malignancy. Cell Signal. 14, 381-395. 
Pan, M.-H., Lai, C.-S., Wu, J.-C., Ho, C.-T., 2011. Molecular mechanisms for chemoprevention of colorectal cancer by natural dietary compounds. Mol. Nutr. Food Res. 55, 32-45.

Paschka, A.G., Butler, R., Young, C.Y.F., 1998. Induction of apoptosis in prostate cancer cell lines by the green tea component, (-)-epigallocatechin-3-gallate. Cancer Lett. 130, 1-7.

Ramos, S., 2007. Effects of dietary flavonoids on apoptotic pathways related to cancer chemoprevention. J. Nutr. Biochem. 18, 427-442.

Rodríguez-Ramiro, I., Martin, M.A., Ramos, S., Bravo, L., Goya, L., 2011. Comparative effects of dietary flavanols on antioxidant defences and their response to oxidant induced stress on Caco2 cells. Eur. J. Nutr. doi10.1007/s00394-00010-00139-00392.

Rodríguez-Ramiro, I., Ramos, S., Bravo, L., Goya, L., Martin, M.A., 2010. Procyanidin B2 and a cocoa polyphenolic extract inhibit acrylamide-induced apoptosis in human Caco-2 cells by preventing oxidative stress and activation of JNK pathway. J. Nutr. Biochem. doi:10.1016/j.jnutbio.2010.10.005.

Sambuy, Y., De Angelis, I., Ranaldi, G., Scarino, M.L., Stammati, A., Zucco, F., 2005. The Caco2 cell line as a model of the intestinal barrier: influence of cell and culture-related factors on Caco2 cell functional characteristics. Cell Biol. Toxicol. 21, 1-26.

Tan, X., Hu, D., Li, S., Han, Y., Zhang, Y., Zhou, D., 2000. Differences of four catechins in cell cycle arrest and induction of apoptosis in LoVo cells. Cancer Lett. 158, 1-6.

Vinson, J., Proch, J., Bose, P., Muchler, S., Taffera, P., Shutta, D., Samman, N., Agbor, G., 2006. Chocolate is a powerful ex vivo and in vitro antioxidant, antiatherosclerotic agent in an animal model, and a significant contributor to antioxidants in the European and American diets. J. Agric. Food Chem. 54, 8071-8076.

Yang, G., Liao, J., Kim, K., Yurkow, E., Yang, C., 1998. Inhibition of growth and induction of apoptosis in human cancer cell lines by tea polyphenols. Carcinogenesis 19, 611-616. 
Yoon, W.H., Lee, S.K., Song, K.S., Kim, J.S., Kim, T.D., Li, G., Yun, E.J., Heo, Y.J., Park, J.I., Kweon, G.R., Koo, S.H., Park, H.D., Hwang, B.D., Lim, K., 2008. The tumorigenic, invasive and metastasic potential of epithelial and round subpopulations of the SW480 human colon cancer cell line. Mol. Med. Rep. 1, 763-768.

Zhou, Y., Wang, Q., Evers, B.M., Chung, D.H., 2005. Signal transduction pathways involved in oxidative stress-induced intestinal epithelial cell apoptosis. Pediatr. Res. 58, 1192-1198. 


\section{Figure captions}

Figure 1. Effect of flavanols on cell viability in (A) Caco-2 cells and (B) SW480 cells after $24 \mathrm{~h}$ of incubation. Values expressed as percent of control are means \pm SD of 4 independent experiments with 2-3 separate samples each $(n=8-10)$. For each isolated flavanol in each plot, bars with the same letter denote similar results; meanwhile, bars with different letters indicate data that are statistically different $(P<0.05)$.

Figure 2. Effect of flavanols on cell proliferation in (A) Caco-2 cells and (B) SW480 cells after 24 $\mathrm{h}$ of incubation. Cell proliferation was calculated as percentage of the relative increase of BrdU incorporated into genomic DNA over the control values. Data represent means \pm SD of 3 independent experiments with 3-4 separate samples each $(n=10-12)$. For each isolated flavanol in each plot, bars with the same letter denote similar results; meanwhile, bars with different letters indicate data that are statistically different $(P<0.05)$.

Figure 3. Effect of ECG on LDH leakage, intracellular ROS generation and GSH concentration in (A, C and E) Caco-2 cells and (B, D and F) SW480 cells. LDH leakage, ROS production and GSH concentration were determined in cells treated with the noted concentrations of ECG during $24 \mathrm{~h}$. LDH leakage is expressed as percent of LDH activity in the culture medium of the total activity, culture medium plus intracellular. ROS production is expressed as arbitrary fluorescence units. GSH values are expressed as percent of control values. Data are means \pm SD of 4 independent experiments with 2-3 separate samples each $(n=6-8)$. For each plot, bars with the same letter denote similar results; meanwhile, bars with different letters indicate data that are statistically different $(P<0.05)$. 
Figure 4. Effect of ECG on the activity of antioxidant/detoxification enzymes in SW480 cells after $24 \mathrm{~h}$ treatment with 10-50 $\mu \mathrm{M}$ ECG for $24 \mathrm{~h}$. (A) GPx, (B) GR and (C) GST activities were measured as described in Materials and Methods. Values expressed as percent of control are means \pm SD of 3 independent experiments with 2-3 separate samples each $(n=6-8)$. For each analyzed enzymatic activity, bars with the same letter denote similar results; meanwhile, bars with different letters indicate data that are statistically different $(P<0.05)$.

Figure 5. Effects of ECG on caspase-3 activity in SW480 cells, levels of Bax, Bad and Bcl- $x_{\mathrm{L}}$ in Caco-2 cells, and Bax, Bad and Bcl- $\mathrm{x}_{\mathrm{L}} / \mathrm{Bcl}-\mathrm{x}_{\mathrm{S}}$ ratio in SW480 cells. (A) Caspase-3 activity (Units/mg protein). (B and D) Bands of representative experiments. (C and E) Densitometric quantification of Bax, $\mathrm{Bad}$ and $\mathrm{Bcl}-\mathrm{x}_{\mathrm{L}}$ levels and $\mathrm{Bcl}-\mathrm{x}_{\mathrm{L}} / \mathrm{Bcl}-\mathrm{x}_{\mathrm{S}}$ ratio. Values are expressed as a percentage relative to the control condition and are means \pm SD of 3 independent experiments with 2-3 separate samples each $(n=7-9)$ for caspase-3 activity assay and with 1-2 separate samples each ( $n=5-6)$ for Western blots. For each analyzed parameter, bars with the same letter denote similar results; meanwhile, bars with different letters indicate data that are statistically different $(P<0.05)$.

Figure 6. Effects of ECG on levels of phosphorylated and total AKT, phosphorylated and total ERK in Caco-2 and SW480 cells. (A and C) Bands of representative experiments. (B and D) Percentage data of p-AKT/AKT and p-ERK/ERK ratios relative to controls. Values are expressed as a percentage relative to the control condition and are means \pm SD of 3 independent experiments with 1-2 separate samples each $(n=5-6)$. For each analyzed parameter, bars with the same letter denote similar results; meanwhile, bars with different letters indicate data that are statistically different $(P<0.05)$. 
Figure 7. Effects of PB2 on the levels of Bax, Bad and Bcl- $x_{L}$, phosphorylated and total AKT, phosphorylated and total ERK in SW480 cells. (A) Bands of representative experiments. (B) Densitometric quantification of Bax, Bad and Bcl- $\mathrm{x}_{\mathrm{L}}$ levels. (C) Bands of representative experiments. (D) Percentage data of p-AKT/AKT and p-ERK/ERK ratios relative to controls. Values are means \pm SD of 3 independent experiments with 1-2 separate samples each $(n=4-6)$. For each analyzed parameter, bars with the same letter denote similar results; meanwhile, bars with different letters indicate data that are statistically different $(P<0.05)$.

Figure 8. Effect of ECG and PB2 and selective inhibitors LY294002 (LY) and PD98059 (PD) on cell viability in (A and B) Caco-2 cells and (C and D) SW480 cells after 24 h of incubation. Cells were incubated with or without $30 \mu \mathrm{M}$ ECG or PB2 for $24 \mathrm{~h}$ in the presence or absence of $50 \mu \mathrm{M}$ PD or $25 \mu \mathrm{M}$ LY. Cell viability was determined by crystal violet and expressed as relative percentage of control cells staining. Data represent means \pm SD of 3 independent experiments with 3-4 separate samples each $(n=8-10)$. For each plot, bars with the same letter denote similar results; meanwhile, bars with different letters indicate data that are statistically different $(P<0.05)$. 
Figure 1.

A

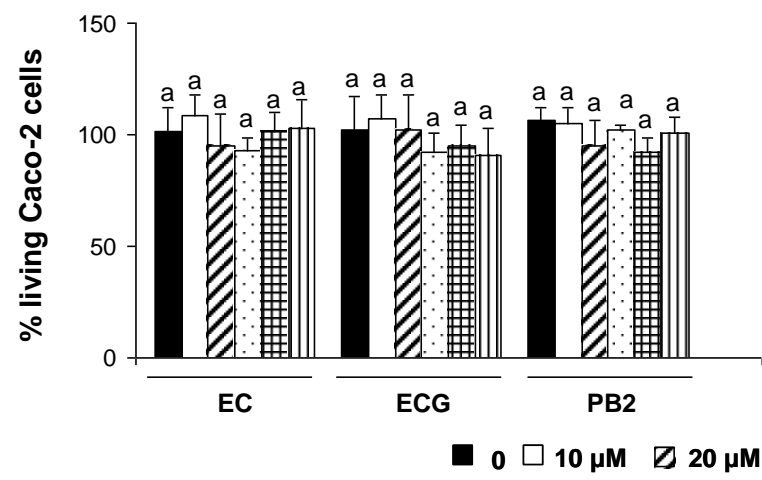

B

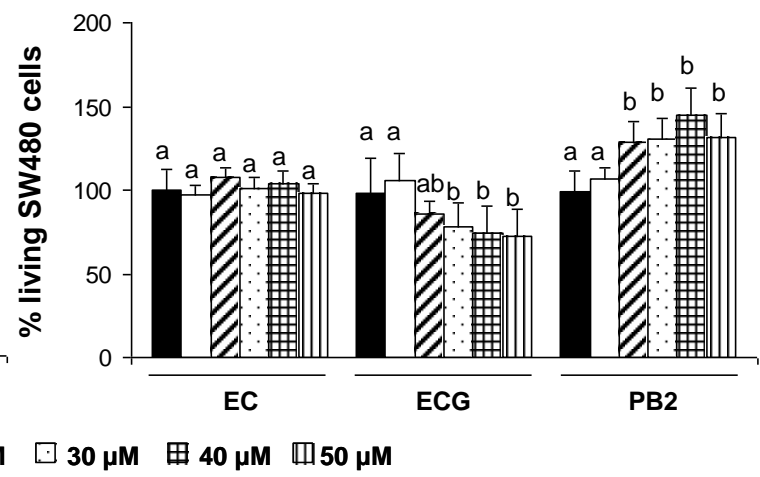


Figure 2.

A

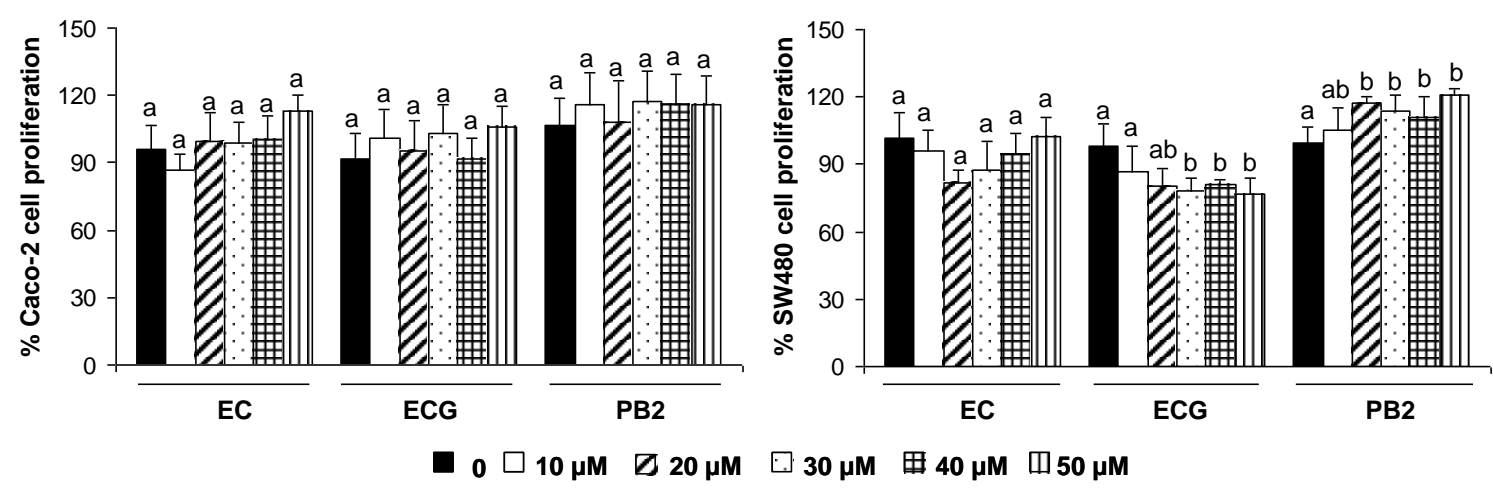


Figure 3.

A

B
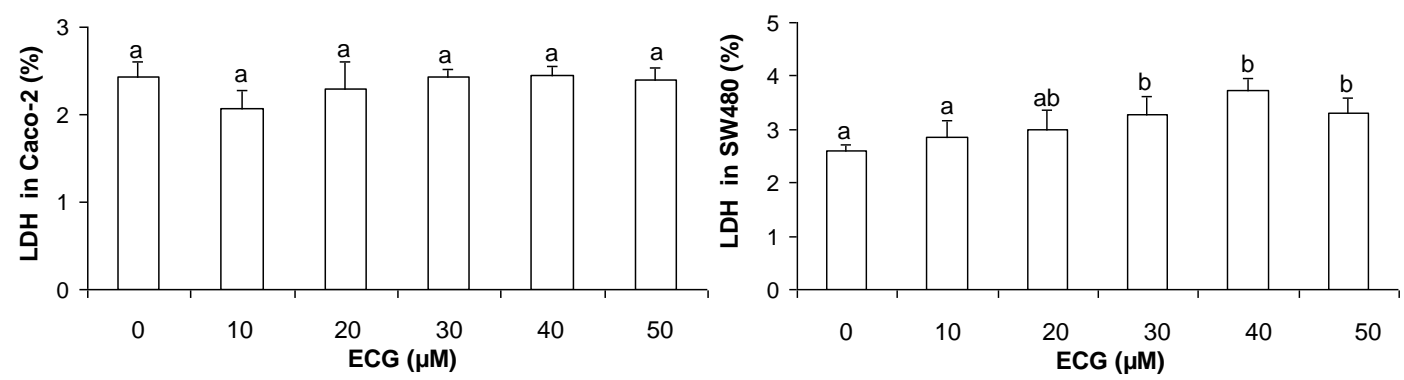

C
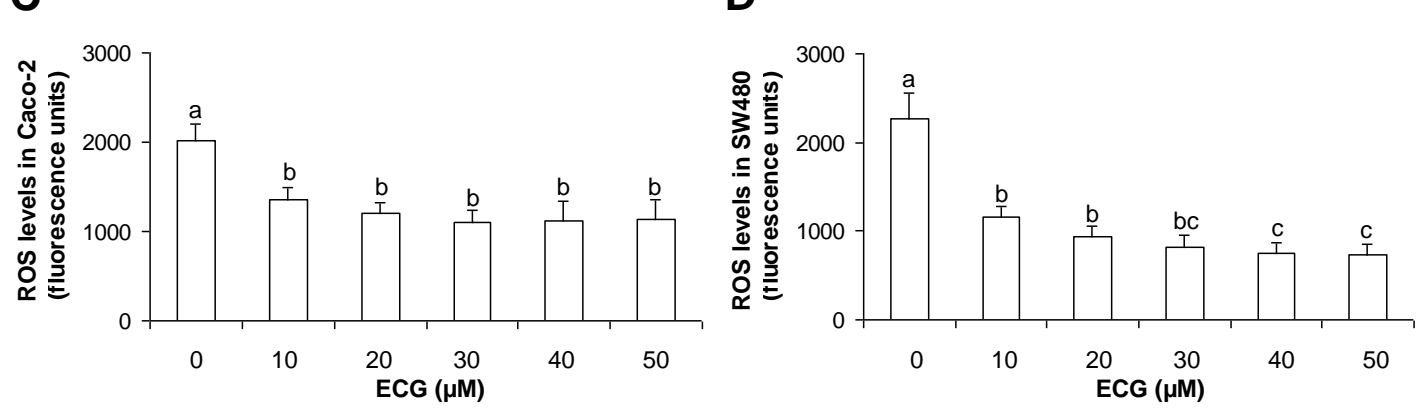

E

F
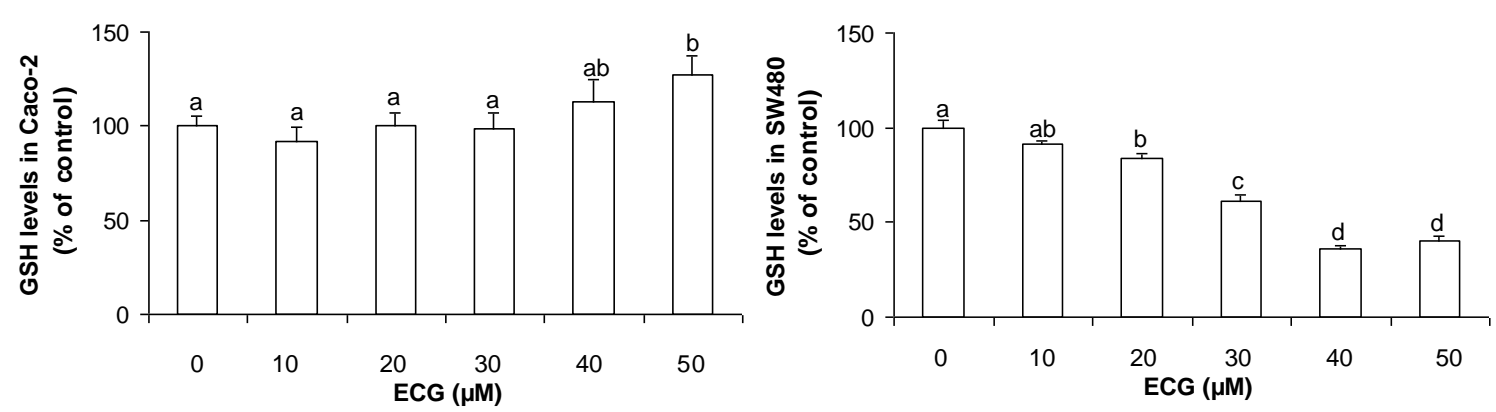
Figure 4.

A

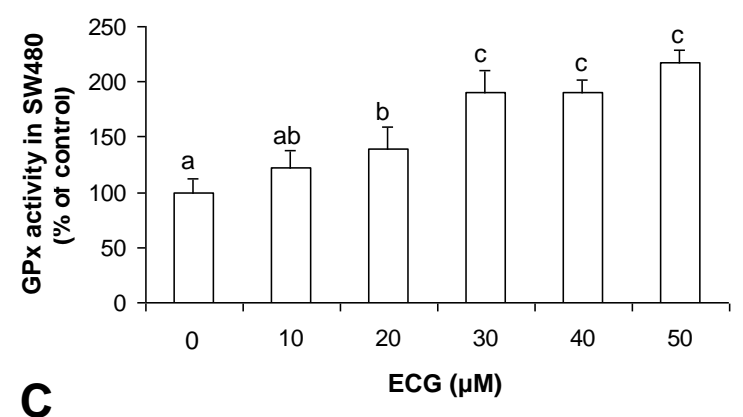

c

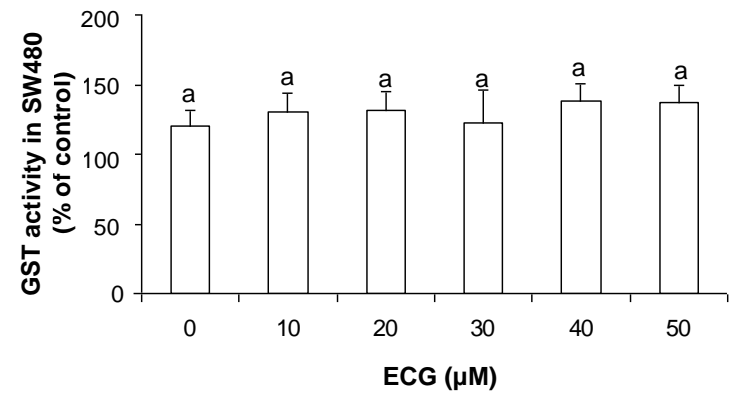

B

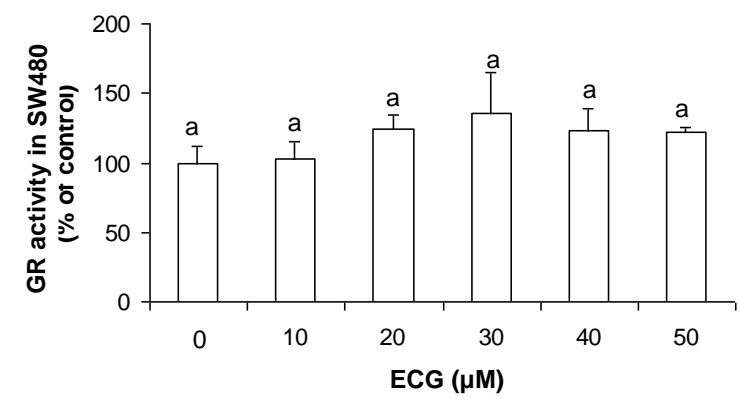


Figure 5.

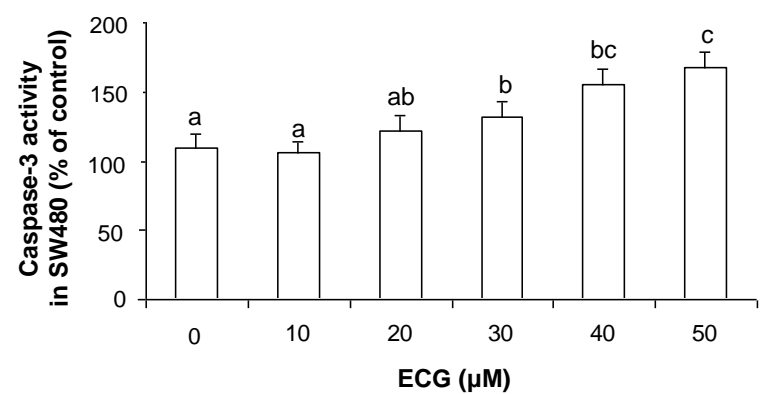

B

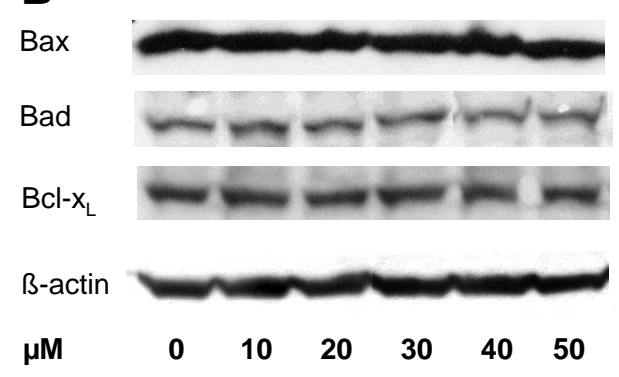

D

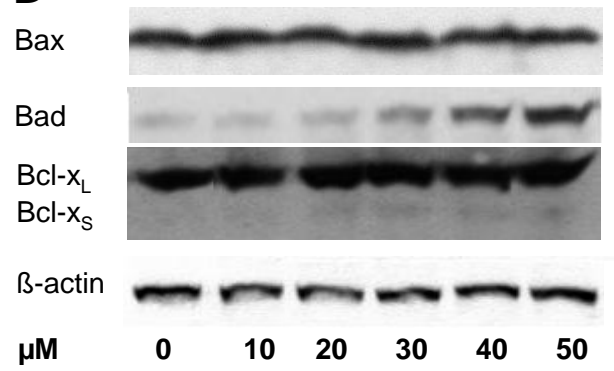

C

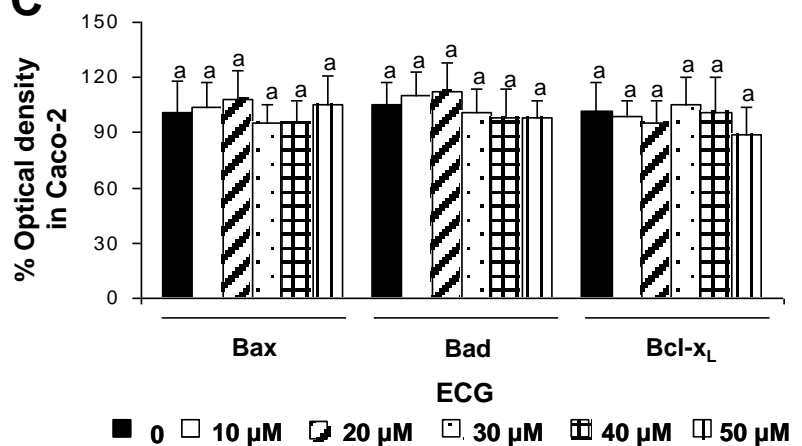

E

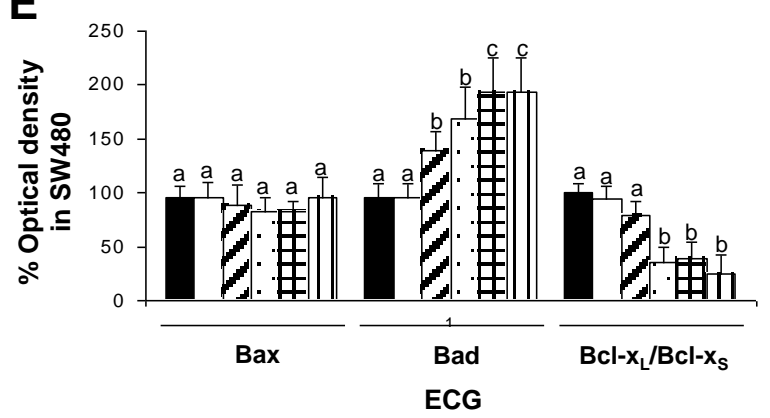

$\square 0 \square 10 \mu \mathrm{M} \square 20 \mu \mathrm{M} \square 30 \mu \mathrm{M}$ 迏 $40 \mu \mathrm{M}$ प $50 \mu \mathrm{M}$ 
Figure 6.

A

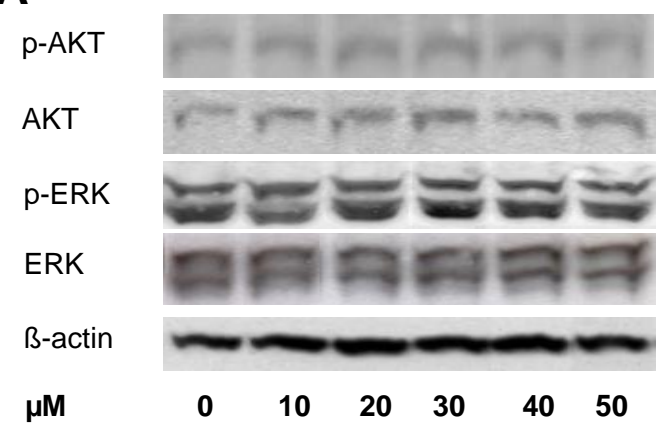

C

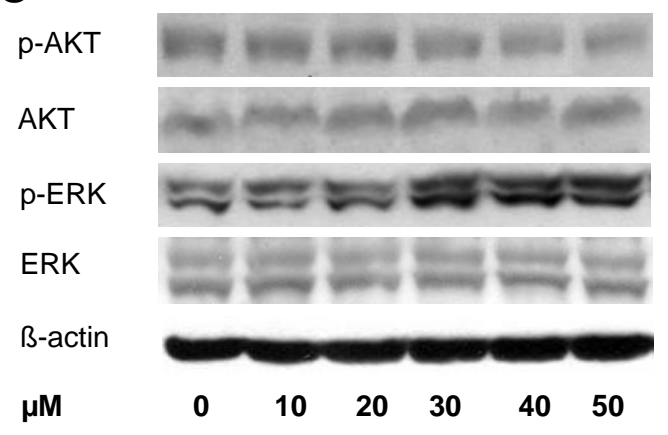

B

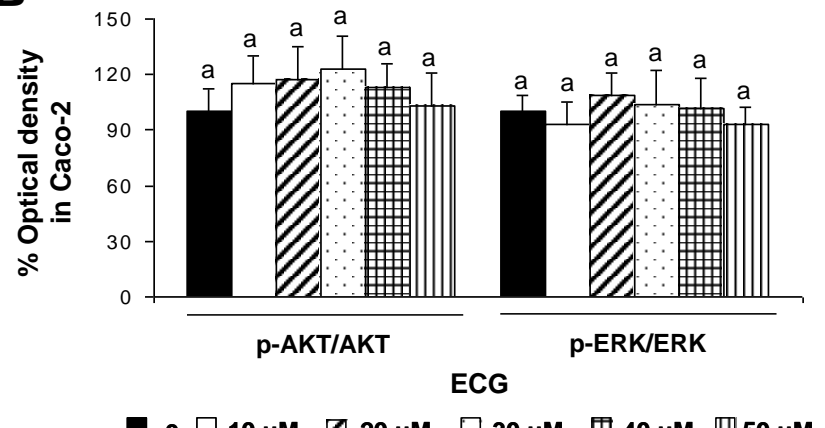

D

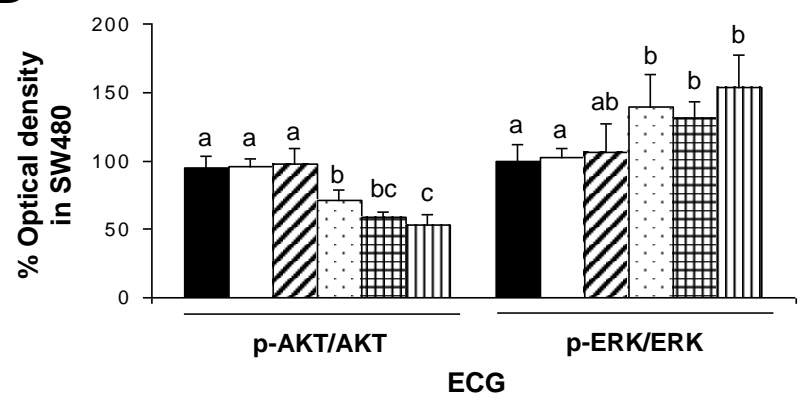

口 0 - $10 \mu \mathrm{M} \square \mathbf{2 0 \mu M} \square \mathbf{3 0 \mu M}$ 田 $40 \mu \mathrm{M}$ 吕 $50 \mu \mathrm{M}$ 


\section{Figure 7.}

A

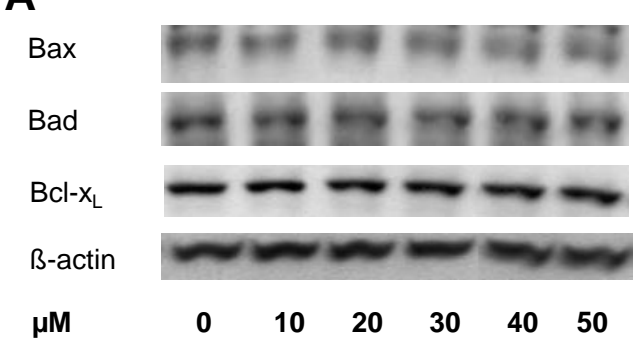

C

p-AKT

AKT

p-ERK

ERK

B-actin

$\mu \mathrm{M}$
B

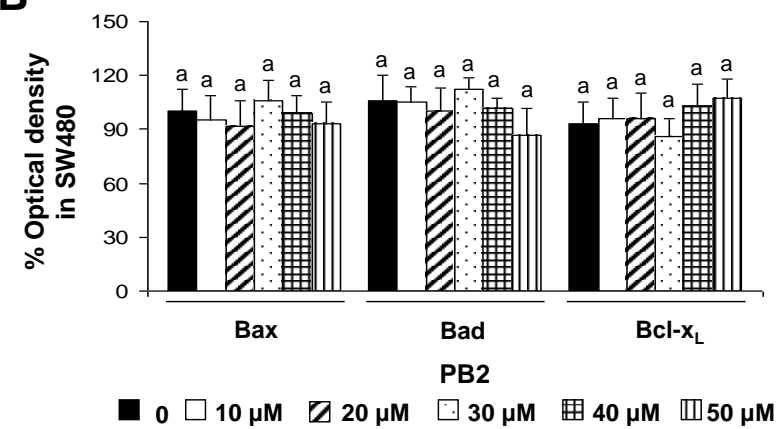

D

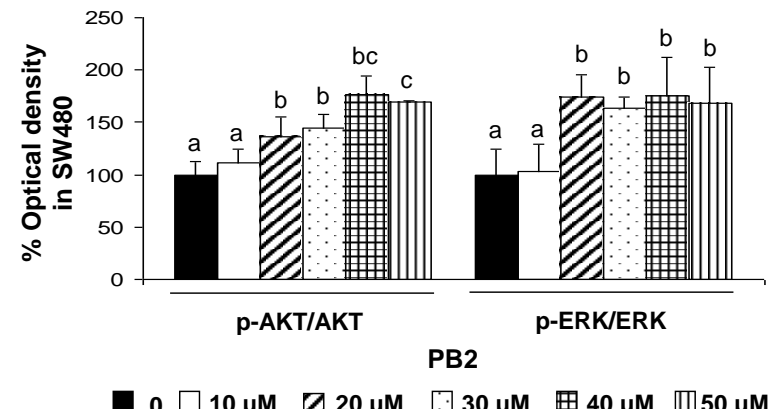


Figure 8.

A

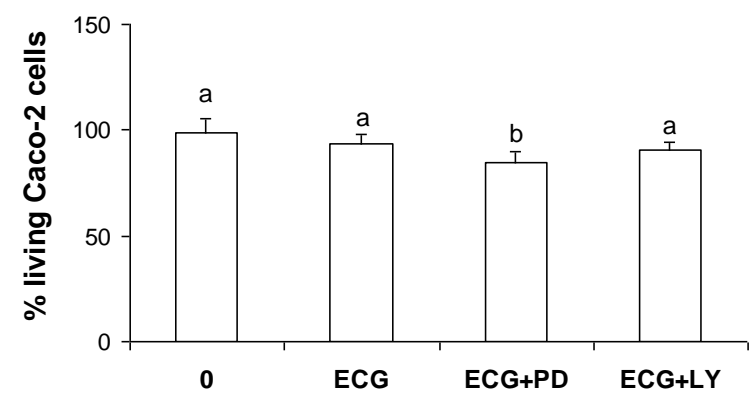

C

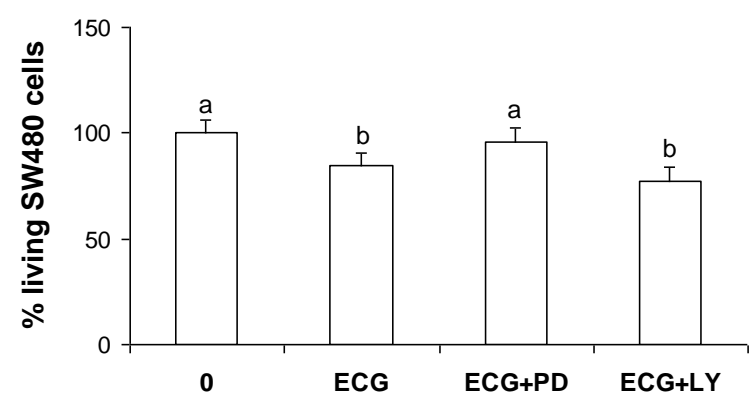

B

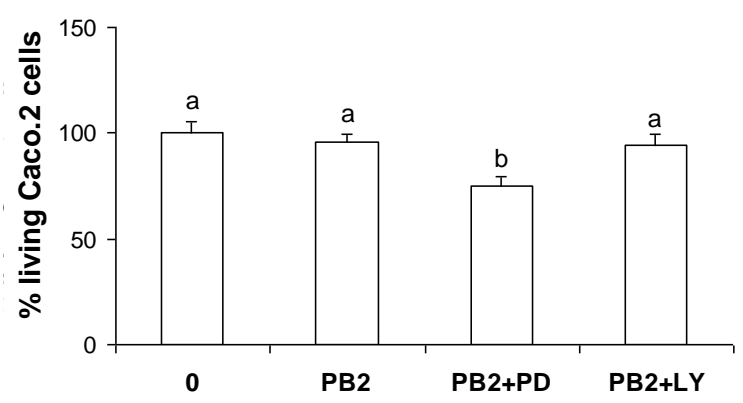

D

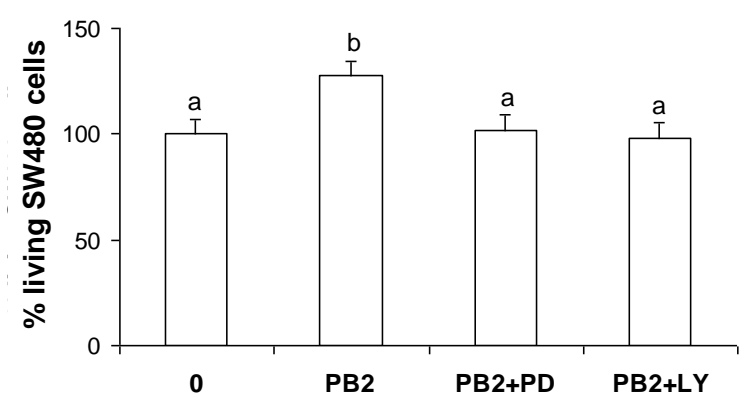

